\title{
Challenges for improving quality of life in Chagas disease
}

\author{
Luiz Fernando Junqueira Junior ${ }^{[1]}$
}

[1]. Laboratório Cardiovascular, Área de Clinica Médica-Cardiologia, Universidade de Brasília, Brasília, Distrito Federal, Brasil.

\section{INTRODUCTION}

In addition to the prevention, control, and treatment of Chagas disease, quality of life and means of improving it is an important concern of health professionals involved in the care of patients affected by the disease. However, despite of this issue to be considered relevant in last 30 years, only in recent years that has it gained greater prominence in the literature and attracted more attention from researchers and those professionals dealing with control and treatment of Chagas disease ${ }^{(1)(2)(3)(4)(5)(6)(7)(8)(9)(10)}$.

Quality of life in any particular disease including Chagas disease is a difficult issue to address owing to its complexity. Quality of life can be defined as the perception of a state of welfare or wellbeing, which involves the interplay of several medical, biological, psychological, social, and cultural factors that affect directly or indirectly the individual in a specific society or society as a whole.

The World Health Organization defines quality of life as, an individual's perception of their position in life in the context of culture and value systems in which they live and in relation to their personal goals, expectations, standards and concerns. Accordingly to The World Health Organization Quality of Life (WHOQOL)-BREF ${ }^{(1)}$ assessment instrument, four broad domains must be considered in evaluation of quality of life: physical health, psychological health, social relationships, and environment; although not included, cultural establishment can be also an important additional domain. The physical health domain includes aspects related to the presence of pain, discomfort, energy level, fatigue, sleep, and rest. The psychological domain includes issues related to positive or negative feelings, selfesteem, body image, and appearance. Meanwhile, the social domain concerns interpersonal relationships, social support, and sexual activity. Finally, the environmental domain considers the perception of physical safety and protection, home environment, financial resources, recreation, leisure, physical environment, transportation, and others.

Corresponding author: Prof. Dr. Luiz Fernando Junqueira Jr. Laboratório Cardiovascular, Área de Clinica Médica-Cardiologia/Faculdade de Medicina/ UnB. Campus Universitário, 70910-900 Brasília, Distrito Federal, Brasil.

Phone: 5561 3107-1938; Fax: 5561 3273-3907

e-mail: 1fjunq@unb.br

Received 12 April 2015

Accepted 17 April 2015
As such, an integrated approach for evaluating quality of life is a complicated task; usually only limited aspects of a certain domain or at most some domains are integrally evaluated. Within this complex conceptual framework, factors related to the demand for adequate healthcare are very important, and these are also factors that constitute the basis for the attainment of quality of life requirements in other domains, representing critical markers of individual good health and welfare. A review published in the Journal of the Brazilian Society of Tropical Medicine addressed the question of health-related quality of life regarding to some clinical, functional, and therapeutic factors in patients with Chagas disease ${ }^{(10)}$. This question about Chagas disease has sparsely been discussed in the literature and thus has great and broad interest. Owing to its unique and diverse nosological, psychological, social, cultural, and environmental peculiarities, improving the quality of life of Chagas disease patients is a substantial challenge, and future studies are expected.

\section{BACKGROUND AND CHALLENGES}

In brief, Chagas disease is an important human infectious parasitic disease caused by the protozoan Trypanosoma cruzi and transmitted by hematophagous triatomid bugs. It is chronically debilitating, physically and psychologically limiting, and incurs high morbidity and mortality. Despite the recent successful and extensive interruption of vectorial transmission in many countries in which the disease is endemic, which has greatly decreased the number of new cases, millions of previously infected people still chronically suffer from it in their more productive phases of life.

Approximately 8-10 million people are chronically infected worldwide, the majority of whom live in many countries of Central and South America and have one of the chronic clinical forms of the disease. Most patients live in underdeveloped socioeconomic conditions in rural areas where healthcare availability is precarious or unavailable. In Brazil, Chagas disease mainly occurs in the northeastern, central-western, and southern regions and more recently has been noted in the Amazon region, with an estimated 2-3 million people (approximately $2 \%$ of the total population) having the chronic forms of Chagas disease ${ }^{(1)(2)(12)(13)(14)(15)(16)}$.

Furthermore, the disease is now spreading to urban areas and non-endemic regions because of migration, blood transfusions, organs transplantation, and the spread of insect vectors. 
Thousands infected immigrants people from Latin American countries, are living in the United States, Canada, Australia, Japan, and European countries. Indigenous chronic cases have also been reported in the southern and southwestern United States ${ }^{(16)(17),}$ totalizing 300,000 cases in this country. In Europe, a total of 24,00039,000 immigrants are estimated to be infected, $7-21 \%$ of whom present with chronic Chagas cardiomyopathy ${ }^{(18)}$. Therefore, Chagas disease represents a serious public health problem that incurs an enormous social burden. In some endemic areas, chronic Chagas heart disease is the most common form of heart disease and early expected death or sudden death.

Chagas disease initially occurs in an acute form that can subsequently develop into one of chronic forms after many years. The indeterminate chronic form, which affects approximately $50-60 \%$ of patients, is characterized by no clinical or functional manifestations detected at the primary diagnostic level; many infected people retain this form for life and have excellent long-term prognosis ${ }^{(12)}{ }^{(15)}$, except for the personal and social stigma as well as the psychological burden of having the disease. Meanwhile, the others $40-50 \%$ have the gross distinctive chronic forms characterized by evolving clinical and functional disturbances of the heart and/or digestive tract, resulting in consequences of varying severity and an estimated 6,000 deaths per year. These disturbances occur exclusively or in association with or without symptoms of varying degree in these forms. Common manifestations of the cardiac form are heart enlargement with progressive heart failure, many various hypokinetic and hyperkinetic arrhythmias, cerebral or pulmonary thromboembolism, cardiac autonomic dysfunction, and expected or unexpected sudden death. In the digestive form, the almost exclusive manifestations are megaesophagus and/ or megacolon. These cardiac and digestive disturbances are those that typically characterize the chronic Chagas disease. The cardiac form is the responsible for the high morbidity and mortality, a high risk of short- and mid-term disability, and poor prognosis of the disease in approximately $30-40 \%$ of affected patients. Many of these patients with heart disease exhibit severe progressive mechanical and/or electrical impairments of the heart, which can result in death from heart failure or lifethreatening arrhythmias ${ }^{(12)(13)(15)(16)(19)(20)}$. Patients with these cardiac and/or digestive chronic forms have more comprised quality of life in several aspects and require more attention.

The peculiar disturbances of variable intensity of cardiac autonomic modulation in many patients are of particular interest in the context of a systemic or integrated view of the organism, considering the integrative action of the autonomic nervous system; however, the functional and clinical implications of the cardiac autonomic dysfunction in Chagas disease are incompletely understood ${ }^{(20)}$. Indeed, considering the important roles of the autonomic nervous system in the control of many organic functions and in involvement in psychological and social tasks, dysfunction of this system may be a risk factor in predispose or trigger cardiac and other functional disturbances as well as psychological and social difficulties that can interact in a complex manner ${ }^{(20)(21)(22)(23)}$. In this context, the integrity of parasympathetic homeostatic function is important for the individual to cope with social stress as well as control emotions, while the heart must provide functional adaptation (21) (22) (23). Therefore, when considering the quality of life of Chagas disease patients, it is important to be aware that they may be prone to psychological derangement and social maladjustment in conjunction with their autonomic cardiovascular adaptive disturbances $^{(1)(4)(8)(24)}$.

Because of these peculiar debilitating and/or disabling characteristics that affect patients' social and psychological wellbeing and physical health, Chagas disease is a dreaded and stigmatizing disease that requires a multidisciplinary approach concerning the quality of life.

\section{OVERCOMING THE CHALLENGES}

Like any other disease, the adequate control of Chagas disease requires patients to have access to an adequate and affordable private or public healthcare system. If so, the disease is likely to be eliminated or at least controlled, improving physical health and alleviating the related psychological and social stresses. These favorable medical and psychosocial changes instigate a positive feedback loop that reinforces these changes in direction to a progressive better global health state, breaking the vicious cycle of disease perpetuation; in turn, this improves the patient's acceptance of the disease, sense of wellbeing, social adjustment, security, and prognosis, all of which result in better quality of life. In contrast, if access to healthcare is difficult, tiring, stressful, and/or of poor quality, the opposite chain of events and consequences occurs; in this case, the disease tends to worsen, compromising quality of life.

Regarding the complex biopsychosocial context of Chagas disease, which encompasses several aspects that can affect quality of life of patients, multidisciplinary attention and actions are warranted to improve it ${ }^{(1)(4)(6)(7)(10)}$. For attaining this, it is firstly critical to deconstruct and dispel the personal, cultural, and social stigma of the disease, which will serve as a starting point for additional actions.

Like other diseases, the overall control of Chagas disease is frequently affected by political contexts of low financial support and efficiency as well as humiliating and degrading public healthcare in environments where access to private care is habitually prohibitive to the majority of population. Most patients with Chagas disease are exposed to these settings.

Despite attempts to provide equal access to healthcare services as well as expectations of efficiency and efficacy, our public healthcare system is also not an open system in which individuals can easily and freely meet their health demands; it is a restrictive system in which only a few fortunate individuals can receive adequate healthcare. However, even such fortunate people often do not receive adequate care because of the technical, operational, and administrative inefficiencies of the healthcare system and of the frequent lack of more extensive engagement by the professionals involved. Consequently, the current system is far from providing ideal or even acceptable health-related quality of life for Chagas disease patients with few exceptions. In places where public authority and health professionals are able to give adequate healthcare, diseased people can attain better quality of life as a result of prompt and satisfactory intervention. 
As mentioned above, eliminating the stigma of Chagas disease is important for improving patient quality of life. All healthcare professionals should be aware of dispelling the fear and stigma of disease in order to improve the quality of life of patients. Chagas disease, with its peculiar nosological, psychological, and social problems, poses a particular challenge for healthcare providers in improving the quality of life of patients. Since its discovery, people have believed the disease to be always fatal or disabling. These beliefs are not baseless, considering the large number of sudden deaths and common complications associated with the disease in endemic regions, particularly in poor rural areas with low socioeconomic status and education levels ${ }^{(12)(14)(15)(16)(19)}$. Although these attitudes still exist, they have significantly decreased, improving patients' quality of life including clinical, psychological, and social aspects. Considering that patients with Chagas disease have distinctive medical, psychological, social and cultural characteristics, it would be interesting to compare the quality of life of patients regarding these differences.

From a medical perspective, there has been great success in the control of all forms of parasite transmission. In addition, there have been advances in the pathophysiological understanding of different manifestations, diagnosis, and treatment. These advances have led to the interruption or delay of the disease course, reducing associated morbidity and mortality; in turn, this has significantly improved the prognosis and daily activities and quality of life of patients with Chagas disease. In particular, the control of arrhythmias by means of artificial pacemakers and implantable cardioverter-defibrillators, surgical procedures, and effective antiarrhythmic drugs (e.g., amiodarone and propafenone) should be highlighted ${ }^{(19)(25)(26)}$. Diuretics, cardioactive and vasoactive therapeutic agents, renin-angiotensin-aldosterone system inhibitors, the alpha/beta-blocker carvedilol, spironolactone, and arterial and venous vasodilators can now better control heart failure(20) (27) (28). Drugs such as beta-blockers, which influence cardiovascular autonomic modulation by increasing parasympathetic activity and reducing sympathetic activity, can also benefit cardiovascular homeostasis by enhancing heart rate variability and hemodynamic status, resulting in marked clinical improvement ${ }^{(20)(27)(28)}$. These therapeutic measures for the principal and more serious manifestations of Chagas disease-related heart disease can favorably influence the subjacent pathophysiological mechanisms and significantly relieve symptoms and enhance physical and mental disposition, work capacity, psychological wellbeing, and social engagement, thus improving quality of life and prolonging lifespan in a great number of patients. Accordingly, in the last 10-20 years, mortality and morbidity rates as well as the number of hospitalizations due to Chagas disease have decreased progressively and significantly $\mathrm{y}^{(15)(16)(19)(20)(26)}$

\section{CONCLUSIONS}

Understanding quality of life requires the detailed and fragmented analysis of its many domains ${ }^{(1)(2)(3)(4)(5)(6)(7) ~(8) ~(9) ~(10) ~(25) . ~ H o w e v e r, ~}$ it is only possible to see the bigger picture of quality of life when these domains are grouped and integrated. This approach allows us to fully judge the state of the physical, social, and psychological wellbeing of Chagas disease patients from the perspective of integrated health expectancy. Although this is a difficult approach, it is nonetheless possible, provided that appropriate integrated multidisciplinary attention may be available by an adequate and efficient healthcare system. Existing examples of this appropriate condition include the praiseworthy and successful initiatives of actions in global healthcare services for patients with Chagas disease in conjunction with the great personal efforts of those engaged towards the bigger picture ${ }^{(1)(2)(3)(4)(6)(7)(8)(10)}$.

\section{CONFLICT OF INTEREST}

The author declare that there is no conflict of interest.

\section{REFERENCES}

1. Storino R. Aspectos Sociales, Económicos, Políticos, Culturales y Psicológicos. In: Storino R, Miles J, editors. Enfermedad de Chagas. Buenos Aires: Mosby Doyma, Argentina; 1994. p. 541546.

2. Gontijo ED, Rocha MO, Torquato de Oliveira U. Perfil clínicoepidemiológico de chagásicos atendidos em ambulatório de referência e proposição de modelo de atenção ao chagásico na perspectiva do SUS. Rev Soc Bras Med Trop 1996; 29:101-108.

3. Guariento ME, Camilo MV, Camargo AM. Situação trabalhista do portador de doença de Chagas crônica, em um grande centro urbano. Cad Saude Publica 1999;15:381-386.

4. Hueb MFD, Loureiro SR. Revisão: Aspectos cognitivos e psicossociais associados a doença de Chagas. Psicol Estud 2005; 10:137-142.

5. Dourado KC, Bestetti RB, Cordeiro JA, Theodoropoulos TA. Assessment of quality of life in patients with chronic heart failure secondary to Chagas' cardiomyopathy. Int J Cardiol 2006; 108:412-413.

6. Gontijo ED, Guimarães TN, Magnani C, Paixão GM, Dupin S, Paixão LM. Qualidade de vida dos portadores de doença de Chagas. Rev Med Minas Gerais 2009;19:281-285.

7. Oliveira BG, Abreu MN, Abreu CD, Rocha MO, Ribeiro AL. Health-related quality of life in patients with Chagas disease. Rev Soc Bras Med Trop 2011; 44:150-156.

8. Ozaki Y, Guariento ME, Almeida EA. Quality of life and depressive symptoms in Chagas disease patients. Qual Life Res 2011; 20:133-138.

9. Pelegrino VM, Dantas RA, Ciol MA, Clark AM, Rossi LA, Simoes MV. Health-related quality of life in Brazilian outpatients with Chagas and non-Chagas cardiomyopathy. Heart Lung 2011; 40:e25-e31.

10. Sousa GR, Costa HS, Souza AC, Nunes MCP, Lima MMO, Rocha MOC. Health-related quality of life in patients with Chagas disease: a review of the evidence. Rev Soc Bras Med Trop 2015; 48:121-128.

11. World Health Organization (WHO). WHOQOL-BREF: Introduction, Administration, Scoring and Generic Version of the Assessment. Field Trial Version. Geneva: WHO; 1996. [Cited 2015 April 9]. Available at: http://www.who.int/en/.

12. Prata A. Clinical and epidemiological aspects of Chagas' disease. Lancet Infect Dis 2001; 1:92-100.

13. World Health Organization (WHO). On behalf of the Special Programme for Research and Training in Tropical Diseases. Reporte del grupo de trabajo cientifico sobre La enfermedad de Chagas. Geneva: WHO; 2007. 
14. Dias JC, Prata A, Correia D. Problems and perspectives for Chagas disease control: in search of a realistic analysis. Rev Soc Bras Med Trop 2008; 41:193-196.

15. Nunes MC, Dones W, Morillo CA, Encina JJ, Ribeiro AL. Chagas disease: an overview of clinical and epidemiological aspects. J Am Coll Cardiol 2013; 62:767-776.

16. Biolo A, Ribeiro AL, Clausella N. Chagas cardiomyopathy Where do we stand after a hundred years? Prog Cardiovasc Dis 2010; 52:300-316.

17. Bern C, Kjos S, Yabsley MJ, Montgomery SP. Trypanosoma cruzi and Chagas' Disease in the United States. Clin Microbiol Rev 2011; 24:655-681.

18. Guerri-Guttenberg RA, Grana DR, Ambrosio G, Milei J. Chagas cardiomyopathy: Europe is not spared! Eur Heart J 2008; 29:25872591.

19. Rassi Jr A, Rassi A, Marin-Neto JA. Chagas' heart disease: pathophysiologic mechanisms, prognostic factors and risk stratification. Mem Inst Oswaldo Cruz 2009; 104 (suppl I):152-158.

20. Junqueira Jr LF. Insights into the clinical and functional significance of cardiac autonomic dysfunction in Chagas disease. Rev Soc Bras Med Trop 2012; 45:243-252.

21. Porges SW. Cardiac vagal tone: a physiological index of stress. Neurosci Biobehav Rev 1995; 19:225-233.

22. Souza GG, Mendonça-de-Souza AC, Barros EM, Coutinho EF, Oliveira L, Mendlowicz MV, et al. Resilience and vagal tone predict cardiac recovery from acute social stress. Stress 2007; 10:368-374

23. McEwen BS, Gianaros PJ. Central role of the brain in stress and adaptation: Links to socioeconomic status, health, and disease. Ann N Y Acad Sci 2010; 1186:190-222.

24. Lima-Costa MF, Castro-Costa E, Uchôa E, Firmino J, Ribeiro AL, Ferri CP, et al. A population-based study of the association between Trypanosoma cruzi infection and cognitive impairment in old age (the Bambuí study). Neuroepidemiology 2009; 32:122-128.

25. Oliveira BG, Velasquez-Melendez G, Rincon LG, Ciconelli RM, Sousa LA, Ribeiro AL. Health-related quality of life in Brazilian pacemaker patients. Pacing Clin Electrophysiol 2008; 31:1178-1183.

26. Gali WL, Sarabanda AV, Baggio JM, Ferreira LG, Gomes GG, Marin-Neto JA, et al. Implantable cardioverter-defibrillators for treatment of sustained ventricular arrhythmias in patients with Chagas' heart disease: comparison with a control group treated with amiodarone alone. Europace 2014; 16:674-680.

27. Botoni FA, Poole-Wilson PA, Ribeiro AL, Okonko DO, Oliveira BM, Pinto AS, et al. Randomized trial of carvedilol after reninangiotensin system inhibition in chronic Chagas cardiomyopathy. Am Heart J 2007; 153:544(e1-e8).

28. Bestetti RB, Otaviano AP, Cardinally-Neto A, Rocha BF, Theodoropoulos TA, Cordeiro JA. Effects of B-Blockers on outcome of patients with Chagas' cardiomyopathy with chronic heart failure. Int J Cardiol 2011; 151:205-208. 